\title{
Investigation of particles with high crack density produced by HPGR and its effect on the redistribution of the particle size fraction in heaps
}

\author{
${ }^{*}$ Y. Ghorbani ${ }^{1}$, A.N. Mainza ${ }^{1}$, J.Petersen ${ }^{1}$, M. Becker ${ }^{1}$, J-P. Franzidis ${ }^{1}$ and J.T. Kalala ${ }^{2}$, \\ ${ }^{1}$ Minerals to Metals Signature Theme, Department of Chemical Engineering, University of Cape Town, \\ Private Bag X6, Rondebosch 7701, South Africa. \\ (*Corresponding author: yousef.ghorbani@uct.ac.za) \\ ${ }^{2}$ Minerals Processing Division, Mintek. Private Bag X3015, Randburg, South Africa
}

\begin{abstract}
The application of comminution technology such as the High-pressure grinding rolls (HPGR), which is able to generate a high density of cracks in the ore particles, is favourable for leaching processes. Extraction of metallic values by the heap leach process, can take place on the particles with partial exposure of mineral grains, if it can provide sufficient surface front for chemical attack by leaching solution. The aim of this study was to assess the benefits of high crack density in the ore particles produced using the HPGR and how it could diminish due to inadequate percolation of the leaching agent.

A zinc ore was comminuted using HPGR at three different pressure settings and with a cone crusher for the control experiment. Subsamples from the $(+23 /-25,+14 /-16,+5.25 /-6.75 \mathrm{~mm})$ size fractions were characterized and packed into leach reactors. The reactors were stopped from time to time to investigate the progress of crack and micro-crack growth and its effect on metal extraction using the X-ray computed tomography (CT). The results are validated with those obtained using traditional techniques such as SEM and QEMSCAN. Investigation of the leach reactors residue indicated significant changes in the particle size distribution (PSD) of initial feed toward the fine size fraction. The residues from the reactors leaching the material prepared using the HPGR product contained more fine particles than the reactors, which were fed by cone crusher product. These differences were up to $10.3 \%$.
\end{abstract}

Key Words: Heap leaching, High-pressure grinding rolls (HPGR), crack density, X-ray computed tomography (CT). 
Heap leaching from low-grade ores has become a major contributor to the total global extraction of economically important metals, notably copper, gold, silver, and uranium (Petersen and Dixon, 2007). Crushed or run-of-mine ore (ROM) is piled on an impermeable pad and leaching reagents are introduced by irrigation from the top. The desired mineral is extracted and the solution becomes increasingly loaded as it percolates through the pile. Leaching may be facilitated by microorganisms resident within the ore bed. The pregnant leach solution (PLS) is collected by a drainage system at the base of the pile and channelled to the PLS pond. The PLS is then pumped to the processing facility where the valuable metal is recovered. The "barsren" leach solution is pumped to the barsren solution pond from where, after solution make-up, it is reapplied to the surface of the heap (Watling, 2006).

Heap and dump leaching offer a number of advantages embracing simple equipment, low investment and operation cost (Acevedo, 2002). In the immediate future, heap leaching is likely to be a major area of expansion (Pradhan et al., 2008). If operated correctly, heap leaching offers economic recovery of resources that would be too marginal for other process routes, such as concentration followed by smelting or autoclaving (Petersen and Dixon, 2007).

The ore granular media used for heap leaching are the porous media packed by ore particles with different sizes, whose permeability is one of the critical parameters influencing the recovery ratio and leaching rate of valuable metals. However, during the leaching process, due to the physical, chemical and biologic reactions in ore, granular media under the role of solution could affect permeability. Therefore, the pore structure continues to evolve and has temporal and spatial variability. The permeability has close relationship with pore structure of ore granular media, therefore it also evolves continuously. For the insitu leaching heaps, recovery ratio and leaching rate decrease year after year. Yang et al., (2008) suggested that this could be due to the permeability evolvement.

Due to larger ore particle sizes encountered in heap leaching, diffusion within the solution filled rock pores always affect extraction rates (Barstlett, 1992; Padilla et al., 2008; Liddell, 2005, Velardo et al., 2002, Vegliò et al., 2001). The mineral grains can be classified according to their accessibility to leach solutions, into different classes (Ghorbani et al., 2011a). The special mineral grain distribution and their accessibility to leach solutions by cracks and pores, plays key role in the rate of extraction. In leaching operations, the creation of fissures and cracks along the mineral ore boundaries and in the minerals allow for access and percolation of leaching fluids. This tends to enhance the recovery of the valuables. 
Hsih et al., (1995), indicated that for hydrometallurgical extraction of metallic values, the mineral grains need not necessarily be liberated as free grains; since partial exposure of mineral grains may provide sufficient surface front for chemical attack by leaching solution. Crack distribution plays a key role in this partial exposure of mineral grains. This relates leaching behaviour to the method by which the ore has been crushed prior to leaching (Unlanda and Szczelina, 2004). High-pressure grinding rolls (HPGR) technology is rapidly gaining wide acceptance within the mineral processing industry (Klymowsky et al., 2002). Benefits, including a superior energy efficiency and a lower overall operating cost of an HPGR based circuit compared to alternative technologies have been demonstrated at a number of operations throughout the world (Apling and Bwalya, 1997; Daniel, 2007; Klymowsky et al., 2002).

The comminution principle, which is compression as a breakage mechanism utilized in the HPGR, is different from that in conventional crushers or tumbling mills where impact and abrasion breakage mechanism are dominant. In the HPGR, contrary to conventional crushing rolls, the particles are broken by compression in a packed particle bed, and not by direct nipping of the particles between the two rolls. This particle bed is created between two choke-fed, counter-rotating rolls. Between these rolls, a particle bed is pressed to a density of up to roughly $85 \%$ of the actual material density (Schönert et al., 1988; Schneider et al., 2009; Aydoğan et al., 2006). As a result, the product from a HPGR is different (Aydoğan et al., 2006), and may be expected to have a different behaviour in downstream processes. Differences in particle porosity and crack network distribution will almost certainly have an influence on the efficiency of the leaching process. Results of studies using the HPGR on semi-refractory gold ore from Nevada and South Africa showed that the leachability of the ores was better after high pressure grinding particularly in the coarser size fractions (Klymowsky et al., 2002). Similarly, the results of several studies on dump and heap leach copper ores from Chile and the US showed that HPGR comminution resulted in an increase in copper extraction when compared to the conventionally crushed ore (Apling and Bwalya, 1997; Daniel, 2007; Klymowsky et al., 2002).

Following the previous study (Ghorbani et al., 2011b), the objective of this study is to assess the benefits of high crack density in the particle comminuted by the HPGR and how it could diminish due to inadequate percolation of the leaching agent.

\section{EXPERIMENTAL METHODS}

The experiments performed for this work were divided into two categories: the first being the comminution of the ore using the HPGR and cone crusher and the second part were leaching in the eight leach reactors. 


\subsection{Ore preparation}

A bulk sample of sphalerite ore was obtained from the Gamsberg Zinc mine in the Northern Cape Province, South Africa. The sample, after primary crushing by jaw crusher, was split and prepared into $250 \mathrm{~kg}$ bags for further crushing by either HPGR or cone Crusher at Mintek in South Africa. HPGR test work was conducted using a Köppern unit equipped with $1 \mathrm{~m}$ diameter rolls and $0.25 \mathrm{~m}$ width that was fully instrumented to control and record hydraulic and nitrogen pressures and throughput. The unit was fitted with profiled Hexadur rolls. The top feed size to the unit was $40 \mathrm{~mm}$ and it was operated at three different pressures (45, 95 and 120 bars). The same top size was fed to the cone crusher and comminuted down to $-25 \mathrm{~mm}$. Products from the cone crusher and HPGR were then screened into five fractions $(+23 /-25,+16 /-23,+14 /-$ $16,+6.75 /-14,+5.25 /-6.75 \mathrm{~mm})$. In this study, subsamples from the following size fractions in the products were subjected to a suite of analysis to study the effect of crack density on the leaching process: $(+23 /-25$, $+14 /-16,+5.25 /-6.75 \mathrm{~mm}$ ). The overview of the sample preparation used for this study is summarised in Figure 1. 


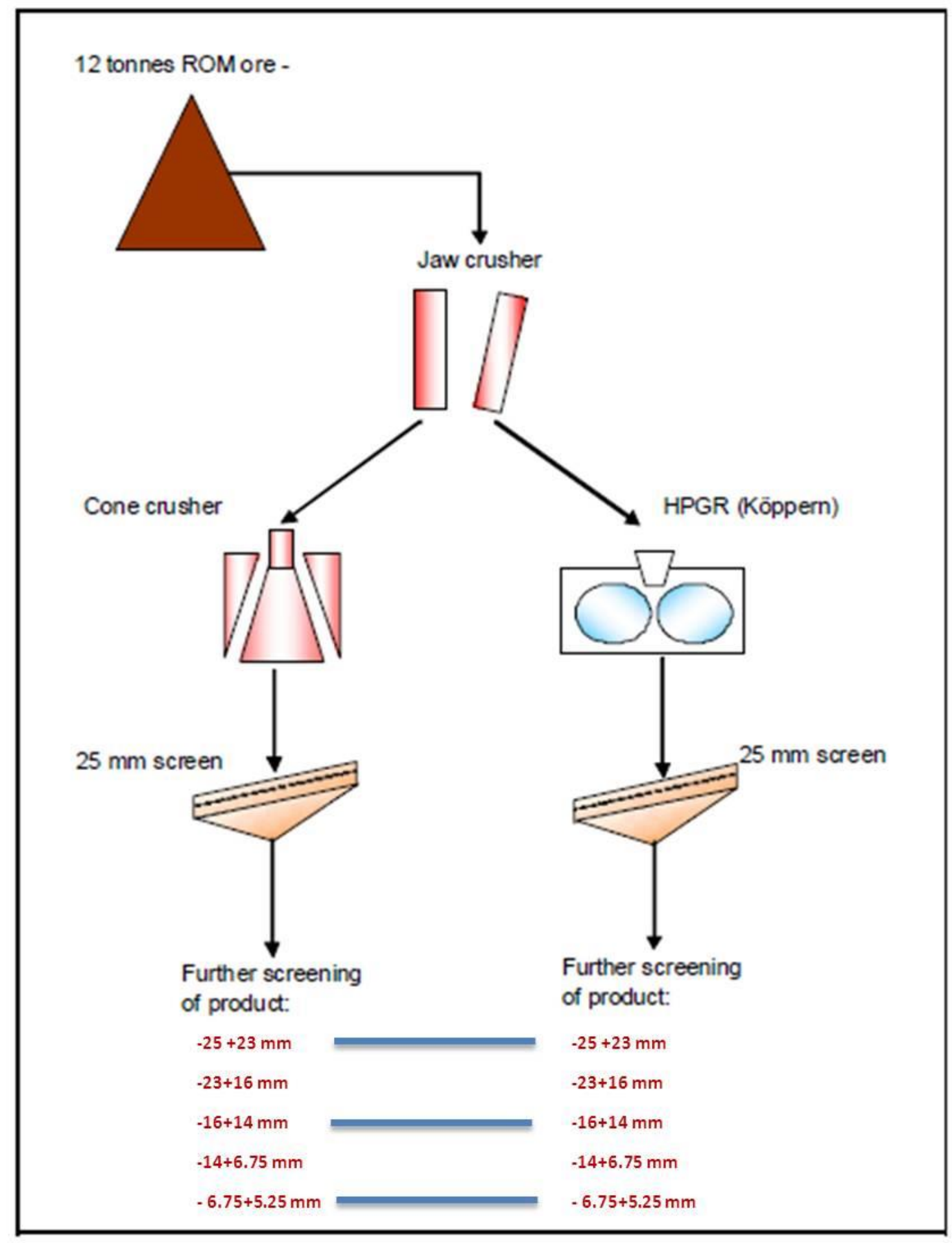

Figure 1: Procedure used for sample preparation. 


\subsubsection{Sample analysis}

3D-dimensional crack distribution in large particles was characterized before and during the leaching process, using the high-resolution X-ray CT system. An HMXST CT scanner at X-Sight X-ray Services in Stellenbosch, South Africa, with 225 kV X-ray source, $3 \mu \mathrm{m}$ resolution reflection target, and interchangeable Nano-tech $1 \mu \mathrm{m}$ transmission target was used. Further details of the X-ray CT specifications are given in Table 1.

Prior to the use of the X-ray CT for investigating the 3-D features of the sphalerite particles, some calibration was needed in order to be able to identify the optimal measurement settings to differentiate between different phases which included the cracks and the various minerals present in the ore particles, given that there is some overlap in the grey level brightness. In practice, density measurement from X-ray tomography data can be obtained either by calibrating the CT machine with objects of known density and obtaining a correlation that relates density with the attenuation coefficient, or by using a dual energy scanning to determine directly the density of the material. In this study, a dual energy scanning method was used for calibration (Ghorbani et al., 2011c), as it allows one to determine both the density and the effective atomic number of the object of interest separately. Thus, the sensitivity of the analysis is significantly increased. Following the reconstruction of the acquired X-ray CT data, the ore particles were analysed using the VGStudio Max 2.1 image analysis software (Volume Graphics GmbH located at Heidelberg, Germany).

Table 1: Experimental conditions used for X-ray CT measurements.

\begin{tabular}{|l|l|}
\hline X-ray energy & $130 \mathrm{kV}$ and $200 \mathrm{kV}$ micro-focus source with $3 \mu \mathrm{m}$ focal spot size \\
\hline X-ray intensity & $120 \mu \mathrm{A}$ beam current \\
\hline Integration frames & $\begin{array}{l}\text { Each projection image was exposed for } 1 \text { second per frame - no integration of } \\
\text { frames }\end{array}$ \\
\hline Random movements & No random movements and continuous rotation of sample \\
\hline Beam hardening filters & $\begin{array}{l}\text { A software correction was used which modifies the Beer-Lambert Law } \\
\text { (attenuation curve) to match the sample. A pre-set correction was chosen }\end{array}$ \\
\hline Second radiation filters & \begin{tabular}{l} 
1mm Cu linear and quadratic curve fitting \\
\hline
\end{tabular}
\end{tabular}


The results are validated with those obtained using traditional techniques such as physical gas (with N2) adsorption, mercury intrusion porosimetry, SEM and QEMSCAN (Ghorbani et al., 2011b, c).

\subsection{Leach experiments}

The aim of these experiments was to compare the effect of comminution devices and breakage mode on metal extraction recovery. The ore samples subjected to leaching tests were comminuted using the HPGR and cone crusher. The details of samples are presented in Table 2. After initial characterization of the ore samples, they were packed into leach reactors (Figure 2a), in which the leach solution was continuously circulated around stacked baskets (Figure 2 b) containing ore particles. Figure $2 c$ shows a schematic drawing of the leach reactor. The particles were fully immersed in leach solution and the reactor was operated in continuous mode. Full details of reactor operation and chemical dynamics during leaching $(\mathrm{pH}$, redox potential, $\mathrm{Fe}^{3+}$ and $\mathrm{Fe}^{2+}$ concentration as well as total $\mathrm{Fe}, \mathrm{Zn}, \mathrm{Mg}, \mathrm{Al}$ and planktonic cell concentration) in the effluent solution are given in Ghorbani et al., 2011d. The reactors were stopped from time to time to investigate the progress of leaching by analysing X-ray CT images of individual tagged particles each time. The results were further validated with those measurements obtained using more traditional, although destructive techniques such as SEM/EDS, QEMSCAN and EMPA. During these stoppages, the solution was kept in the reactors and the sample from the solids phases was taken out (and later replaced) by lifting out the basket stack. During stoppages, careful characterisation of the attached microbial population was also conducted (Ghorbani et al., 2011d).

Table 2: Ore samples investigated.

\begin{tabular}{|c|c|c|c|}
\hline \multicolumn{4}{|c|}{ Comminution devices } \\
\hline \multicolumn{3}{|c|}{ HPGR } & \multirow{2}{*}{ cone crusher } \\
\hline 45 bars & 95 bars & 120 bars & \\
\hline Large $(-25+23) \mathrm{mm}$ & $\begin{array}{l}\text { Large }(-25+23) \mathrm{mm} \\
\text { Medium }(-16+14) \mathrm{mm} \\
\text { Small }(-6.75+5.25) \mathrm{mm}\end{array}$ & Large $(-25+23) \mathrm{mm}$ & $\begin{array}{l}\text { Large }(-25+23) \mathrm{mm} \\
\text { Medium }(-16+14) \mathrm{mm} \\
\text { Small }(-6.75+5.25) \mathrm{mm}\end{array}$ \\
\hline
\end{tabular}




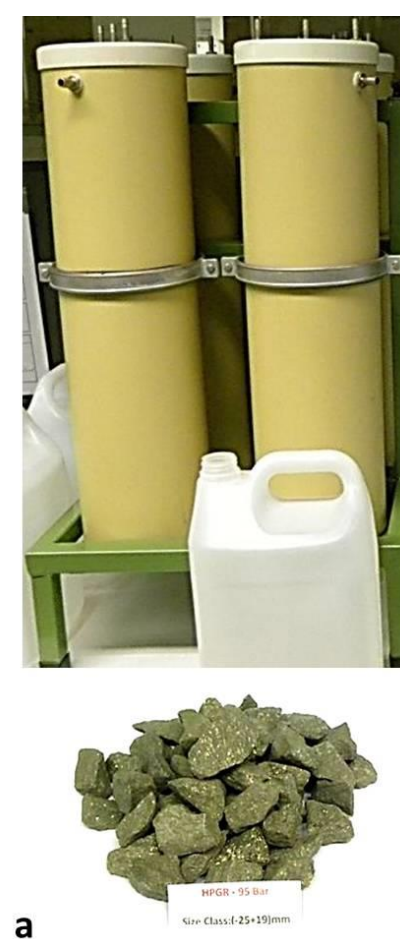

a Large particle size
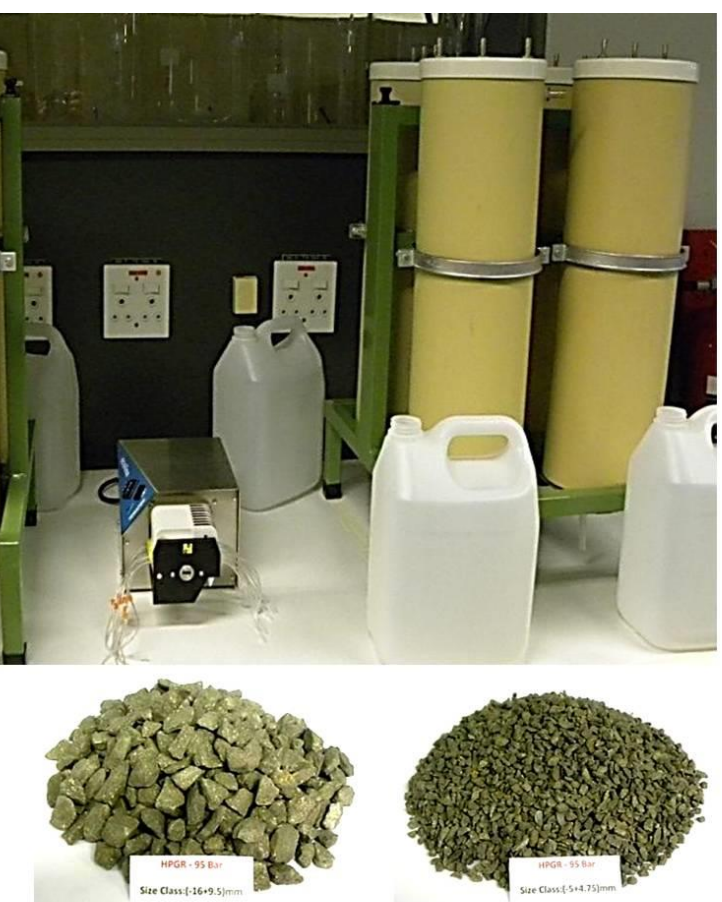

Medium particle size
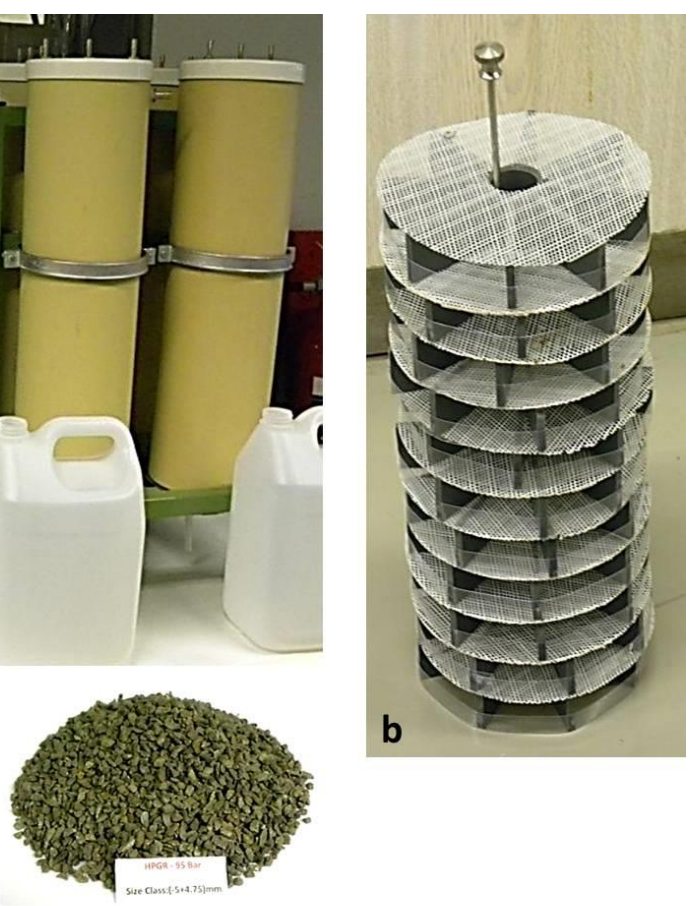

Small particle size

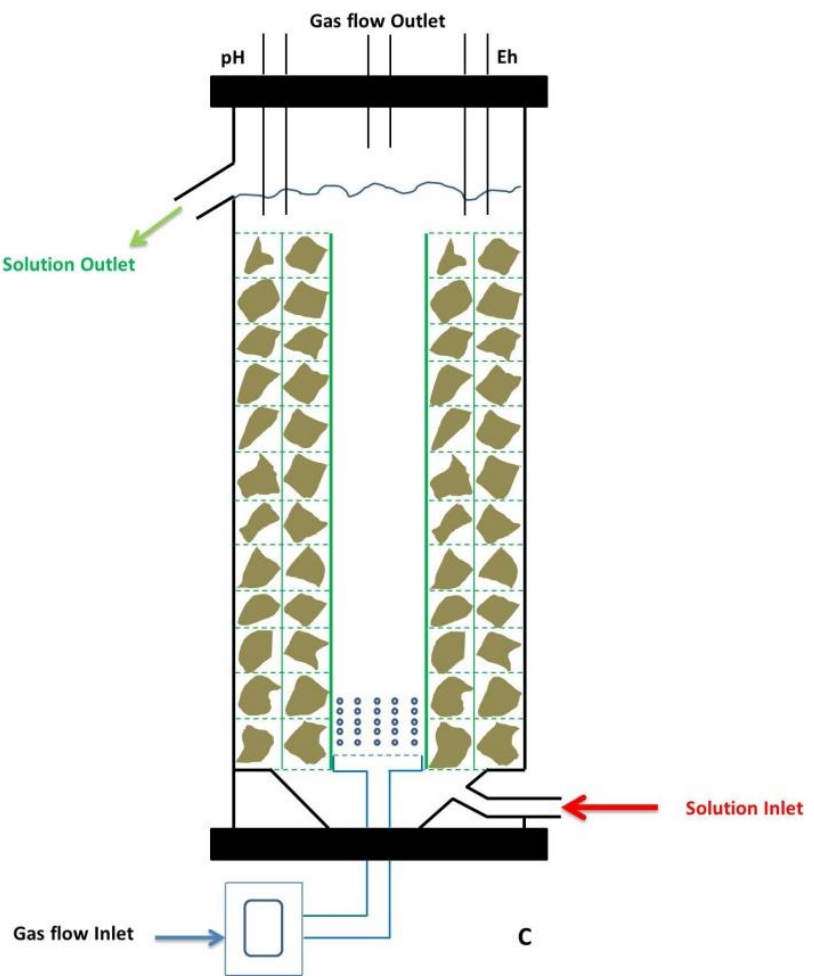

Figure 2: Leach columns, set up of leach reactors with stand and 8-channel pump-head (a), designed frame inside the leach reactor loosely holding individual labelled particles (b), a schematic drawing of leach reactor (c). 
In this section, the effect of comminution devices on crack density, particle size and leaching process has been described and discussed.

\subsection{Effect of comminution device on crack network}

It was shown by Ghorbani and co-workers (Ghorbani et al., 2011b, c), that particles comminuted using the HPGR results in formation of micro-cracks in the ore material, especially when compared to the material prepared by the cone crusher. Particle characterisation consistently identified the prevalence of the microcracks and higher porosity for particles prepared by the HPGR, which employs compression breakage as dominant breakage mechanism when compared to those, comminuted using the cone crusher.

The HPGR tests were performed at three different pressure settings of 45,95 and 120 bars, which correspond to the specific grinding forces of $1.42,3.00$ and $3.79(\mathrm{~N} / \mathrm{mm} 2)$ respectively (Table 3$)$. The results of the X-ray CT appeared to indicate that more micro-cracks were present in the products obtained from the HPGR operated at the pressure setting of 95 bars. This suggests that for the HPGR device used in this work, the best pressure setting to produce particles with more micro-cracks is around 95 bars. Further increase in pressure did not appear to give a finer product or more micro-cracks, which are favourable for heap leaching (Ghorbani et al., 2011b, c). The specific energy associated with the three pressure settings used in the experiments is given in Table 3.

Table 3: The specific energy and grinding force at the different pressure of HPGR.

\begin{tabular}{ccc}
\hline Pressure(bars) & Specific grinding Force(N/mm2) & Specific Energy(kWh/t) \\
\hline 45 & 1.42 & 0.81 \\
95 & 3.00 & 1.74 \\
120 & 3.79 & 2.16 \\
\hline
\end{tabular}

As Table 4 shows HPGR required the lowest specific energy consumption and achieved a reduction of $28 \%$ over the cone crusher. It should be note that the difference in the products $\left(p_{80}\right)$ compared to the feed $\left(f_{80}\right)$ 
Was used to calculate $28 \%$ more size reduction in the HPGR crushed particles compared to the cone crushed particles. Calculation of the cone crusher energy requirements was based on the Bond work index at a sieve size of $150 \mu \mathrm{m}$. This coarser screen size provides a lower estimate for the energy requirements of a cone crusher.

Table 4: The specific energy of HPGR-95 bars and cone crusher.

\begin{tabular}{l|c|c|c}
\hline Comminution devices & Feed $\mathbf{f}_{80}(\mathbf{m m})$ & Product p $_{80}(\mathrm{~mm})$ & Specific Energy(kWh/t) \\
\hline Cone Crusher & 32 & 19 & 1.91 \\
HPGR -95 bars & 32 & 10 & 1.74 \\
\hline
\end{tabular}

Figure 3 shows particle size distribution (PSD) of the products from the HPGR and cone crusher tests. It can be seen that HPGR products from the three pressure settings were finer than the cone crusher product.

As discussed in introduction, in the HPGR the particles are broken by compression in a packed particle bed; this compression is achieved by applying high pressure, which was allowed to reach 120 bars in this study, exceeding the compression strength of the feed material. During this compacting process, the material is ground to a wide particle size distribution with a large proportion of fines, compacted into flakes. Although a finer product size distribution is expected as the pressure increases, the finest product in this work was obtained when HPGR was operated the pressure setting of 95 bars which corresponded to the specific grinding force of $3.00\left(\mathrm{~N} / \mathrm{mm}^{2}\right)$. The compressive force not only acts on the coarse end of the particle size distribution (PSD), but throughout the particle bed on both coarse and fine particles, including the fine particles derived from the initially coarser fractions (Schneider et al., 2009, Apling and Bwalya, 1997; Klymowsky et al., 2002). 


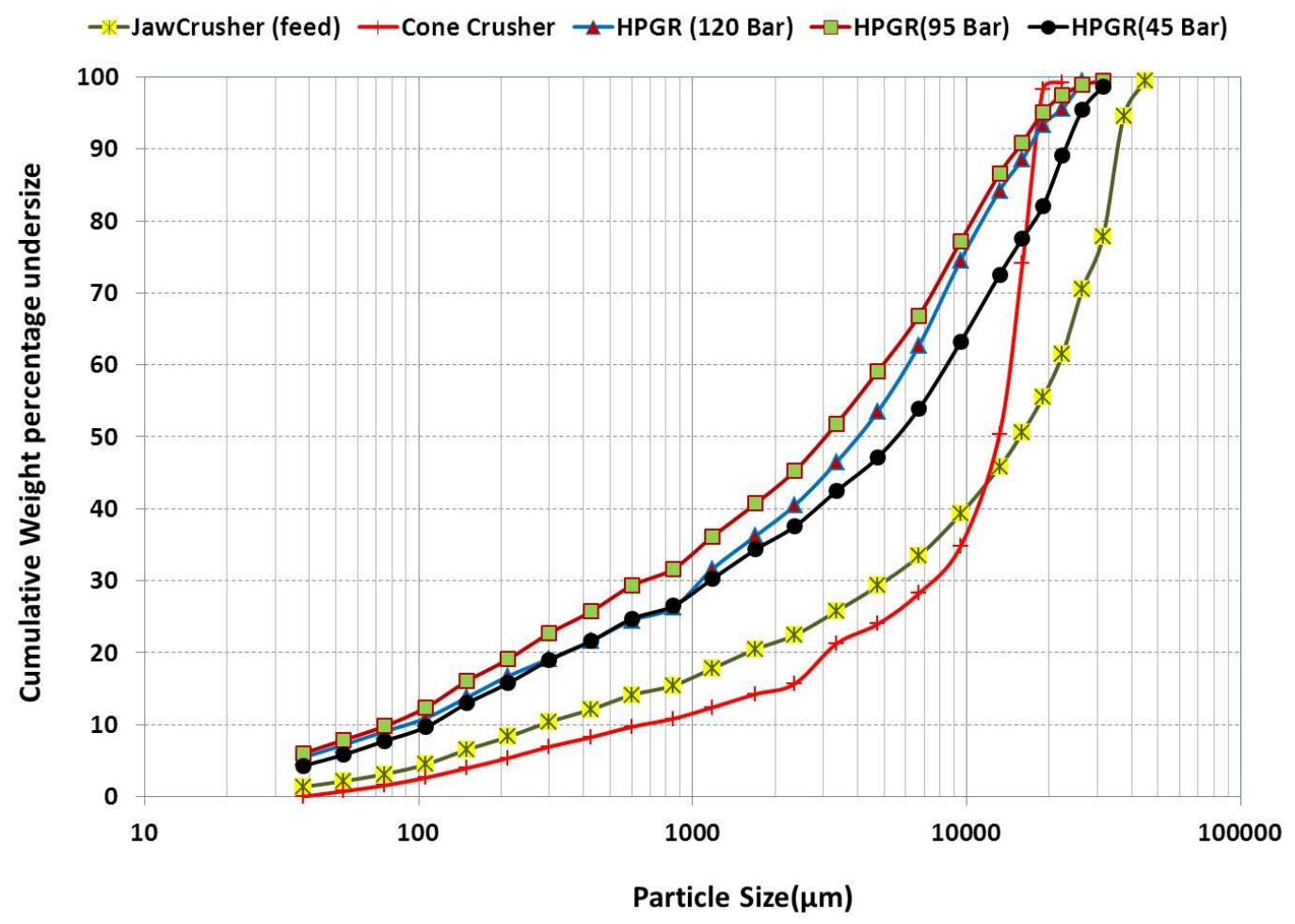

Figure 3: Product particle size distribution (PSD) from the tests performed using the cone crusher and three pressure settings of the HPGR.

\subsection{Advantage of micro-cracks on heap leaching process}

The implications of the high crack density, is that the large sphalerite-bearing particles prepared by the HPGR are likely to be more suitable to leaching, since the presence of these micro-cracks provides an additional surface-front of valuable mineral grains for chemical attack by the leaching solution.

Figure 4 shows an image of the cross-section of one of the labelled large sphalerite ore particles comminuted using HPGR at 95bars with the vein shape of the grain exposed to the leach solutions via pores or cracks. Accessibility to leach solutions by cracks accelerates the dissolution of the mineral grains, although they are inside the ore particle. 


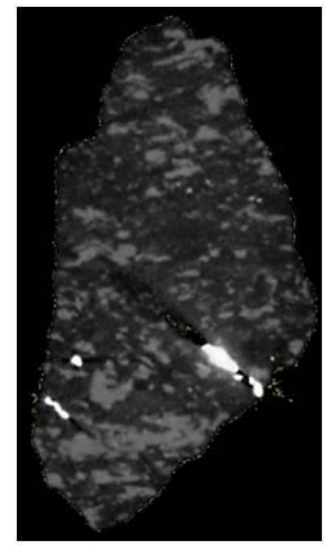

Before treatment

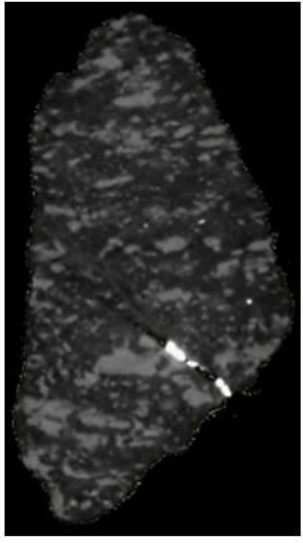

After one month

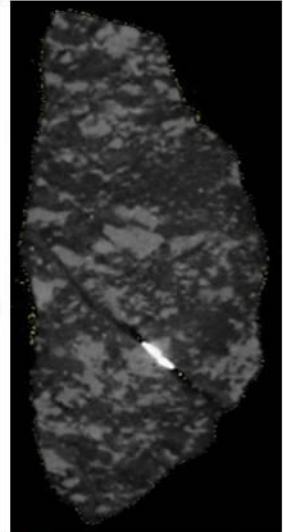

After three months

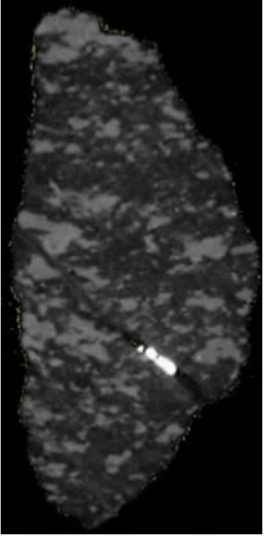

After six months

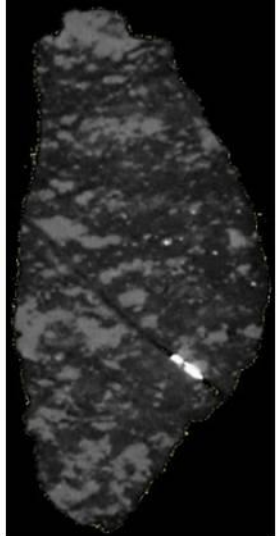

After eight months

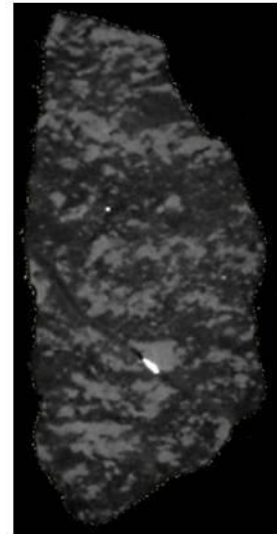

After eleven months

Figure 4: Plane images of the mineral grain within the single sphalerite ore particle and their accessibility to leach solutions by cracks and pores.

Figure 5 and Figure 6 show the crack network for particles comminuted by the HPGR and cone crusher respectively. The crack network in the particles comminuted by the HPGR appeared to increase during the leaching process (Figure 5). This accelerates reagent diffusion into the particles resulting in more metal extraction. However, no significant change was observed in the crack network for the particles comminuted using the cone crusher (Figure 6). High crack density within the ore particles provides higher prevalence of attachment sites for microorganisms, which would provide for regeneration of ferrous to ferric iron as leach reagent closer to the mineral surface (Rodríguez et al., 2003). Initial microbial activity on the surfaces of the sulphide minerals occurs mostly along former cracks, fractures, lineation, grain boundaries, and zone contacts, contacts between different generations or compositions, etc. (Africa et al. 2010, Ghorbani et al., 2011d). Mechanical imperfections are deviations in the sulphide crystal structures to which microorganisms become preferentially attached. Such defects usually contain high amounts of strain energy, which when released could be of use to the microorganisms during the oxidation process. The rate of oxidation is expected therefore to be higher at sites of defects containing such strain energy (Tromans and Meech, 2002, Ubaldini et al., 1997). 


\section{Crack network growth during the leaching}

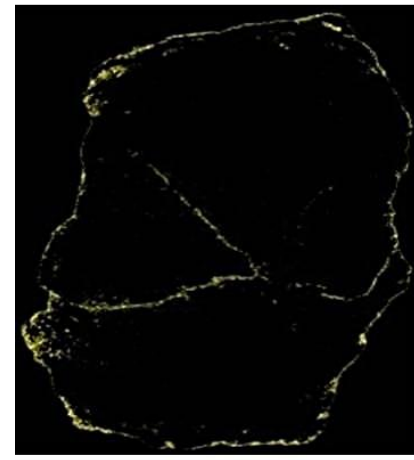

Before treatment

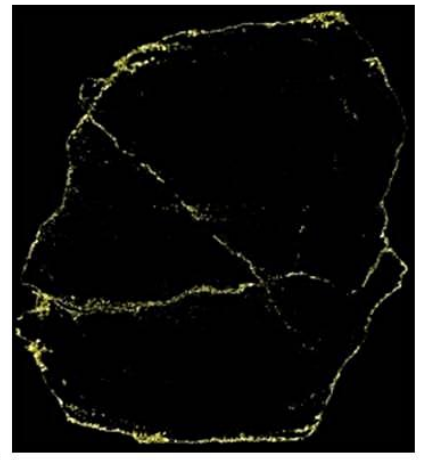

After three months

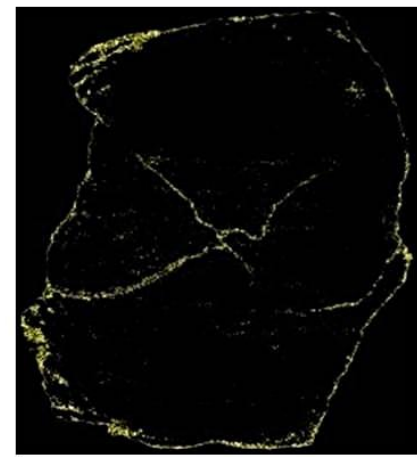

After six months

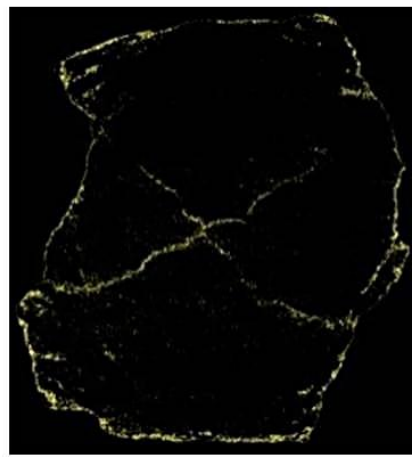

After eleven months

Figure 5: Crack network growth during the leaching for the particles comminuted by HPGR.

\section{Crack network growth during the leaching}

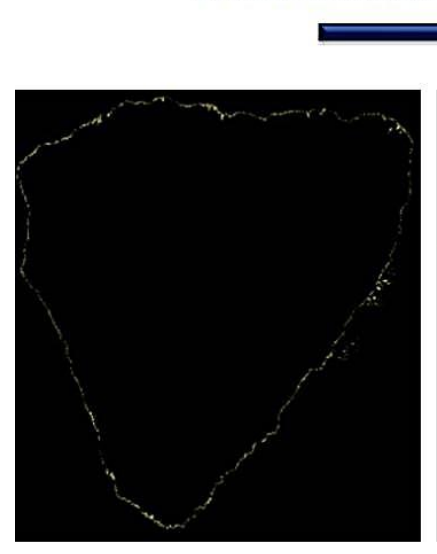

Before treatment

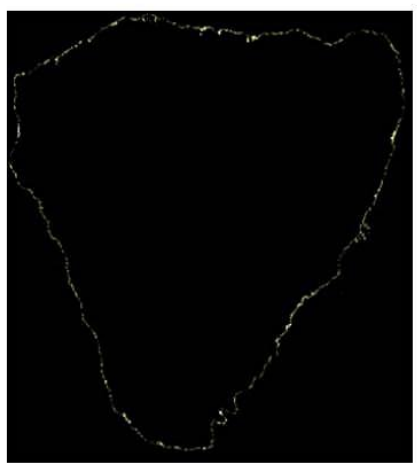

After three months

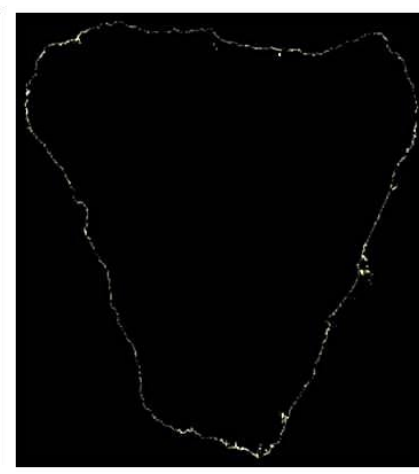

After six months

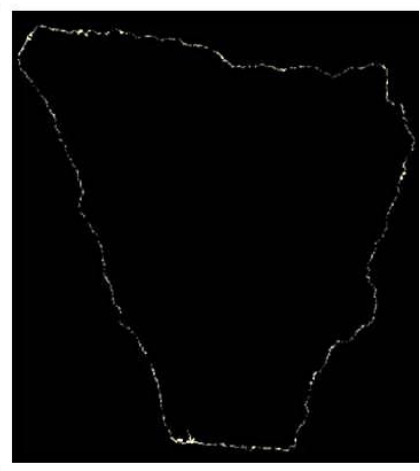

After eleven months

Figure 6: Crack network growth during the leaching for in the particles comminuted by cone crusher.

\subsection{Effect of HPGR product on percolation of heap leaching}

In this study, similar size fractions for the ore were selected from the products of the material comminuted using the HPGR and cone crusher and subjected to leaching tests. Differences in particle porosity and crack network distribution will almost certainly have an influence on the efficiency of the leaching process. Figure 7 compares the percentage of zinc extraction over 11 months of leaching from ore comminuted by HPGR 
and cone crusher. This confirms that the leachability of the ores was better for products prepared using the HPGR compared to those from the cone crusher. Figure 8 shows higher metal extraction for particles prepared using the HPGR operated at the pressure setting of 95 bars compared to the 45 bars and 120 bars pressure settings. This indicates that there is an optimum operating pressure where the metal extraction rates are higher.

The micro-fracturing observed in the feed prepared using the HPGR could be the major reason for difference in the zinc extraction in each of the size fractions evaluated. The results obtained in this work showed that a 10 to $15 \%$ additional zinc leach extraction is possible (Figure 7).

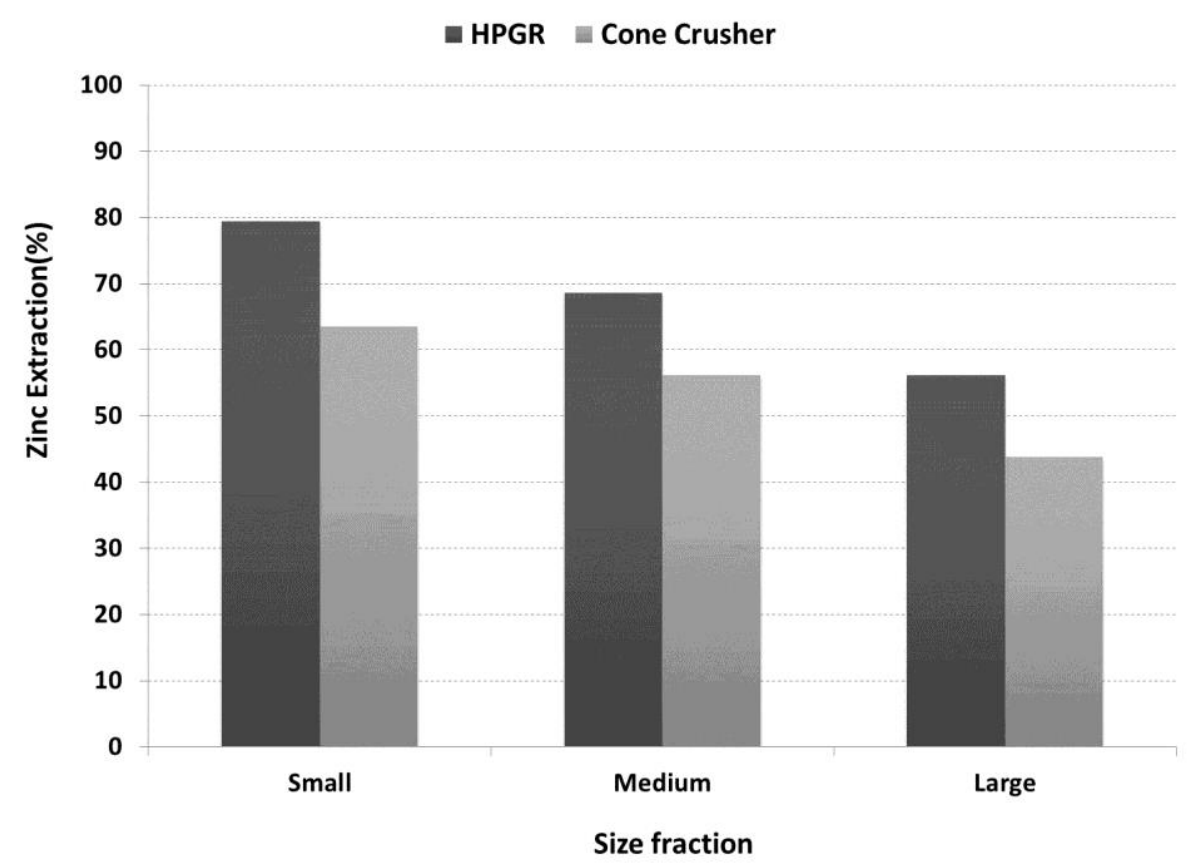

Figure 7: Comparison of the leachability of the HPGR product versus cone rusher. 


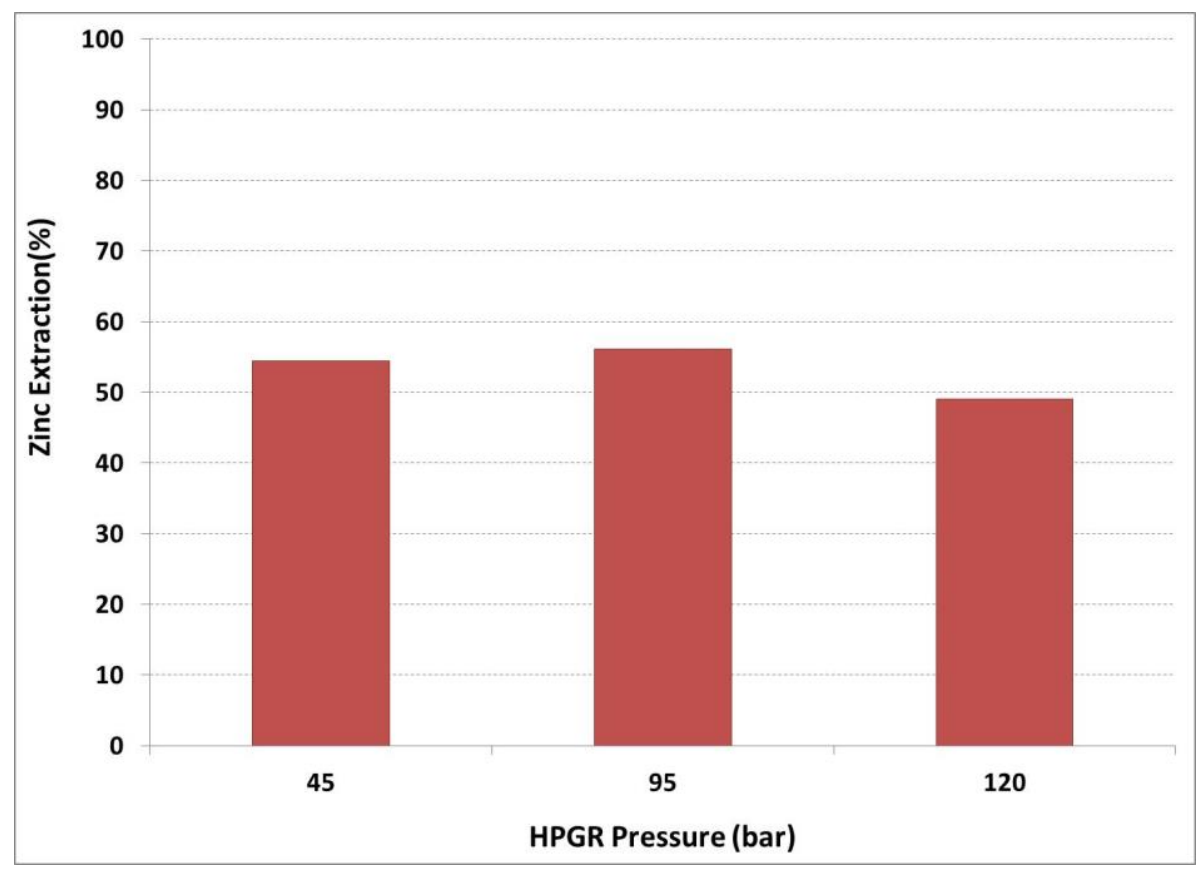

Figure 8: Comparison of the leachability of the HPGR product in the different pressure settings.

The HPGR products for at all pressure settings were finer than that of the cone crusher (Figure 3). It is known that the presence of excess fines in heap leaching operations may cause low recovery due to reduced heap permeability and/or channelling of lixiviant flow. These problems are mitigated to some extent by agglomeration pre-treatment prior to heap leaching (Kodali et al., 2011; Yang et al., 2008). In this work, the feed material to the leach reactors had the same selection of the sieve ranges for both the HPGR and cone crusher tests. Eight reactors were prepared and fed with particles in specific size classes produced using either the HPGR or the cone crusher given in Table 2. Evaluation of the leach reactors residue indicated significant changes in the PSD compared to the feed as shown in Figures 9 to Figure 11 for different size fractions of HPGR and cone crusher products. 


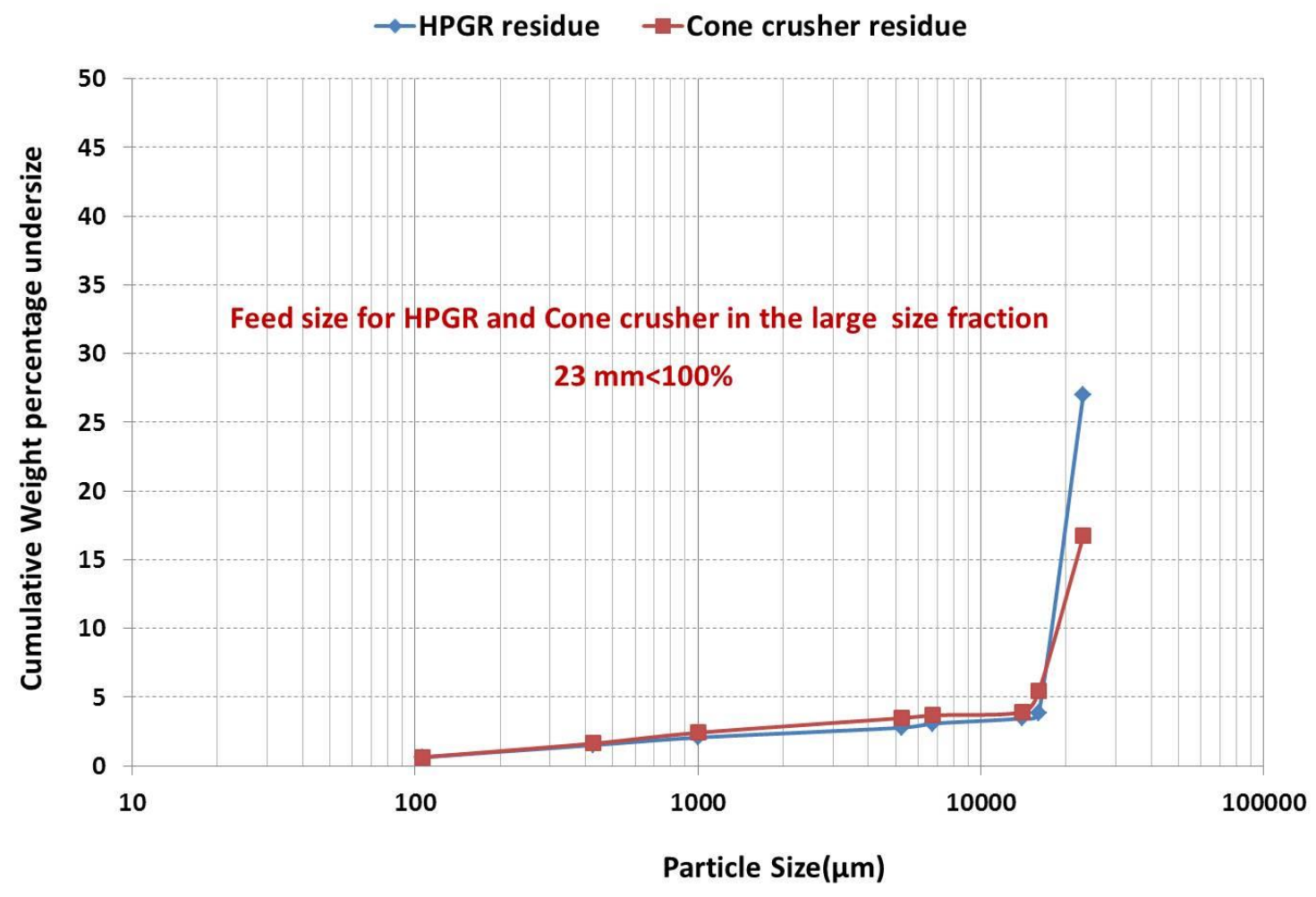

Figure 9: Changes in the PSDs of the HPGR and cone crusher products after 11 months leaching process in of the large size fraction.

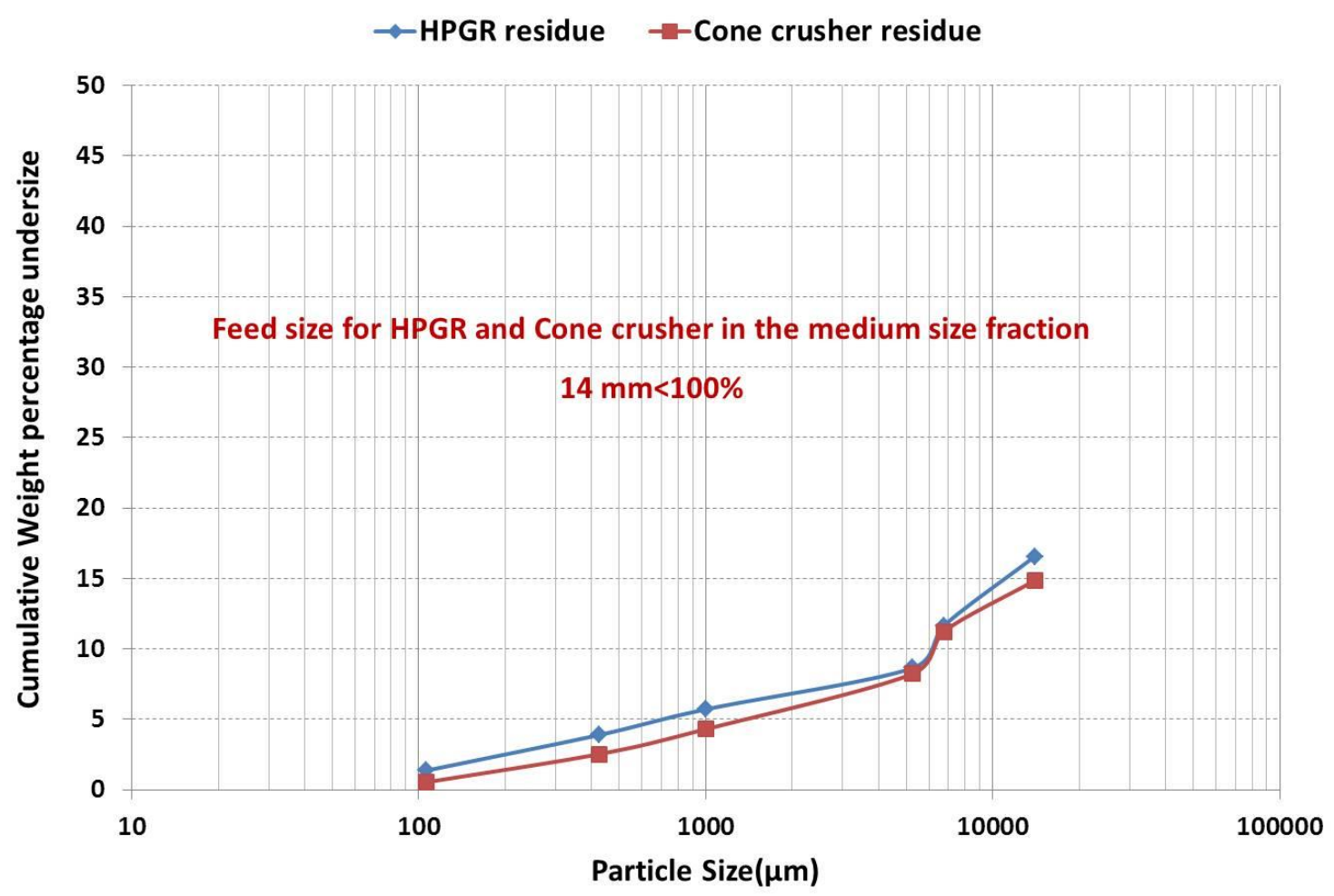

Figure 10: Changes in the PSDs of the HPGR and cone crusher products after 11 months leaching process in of the medium size fraction. 


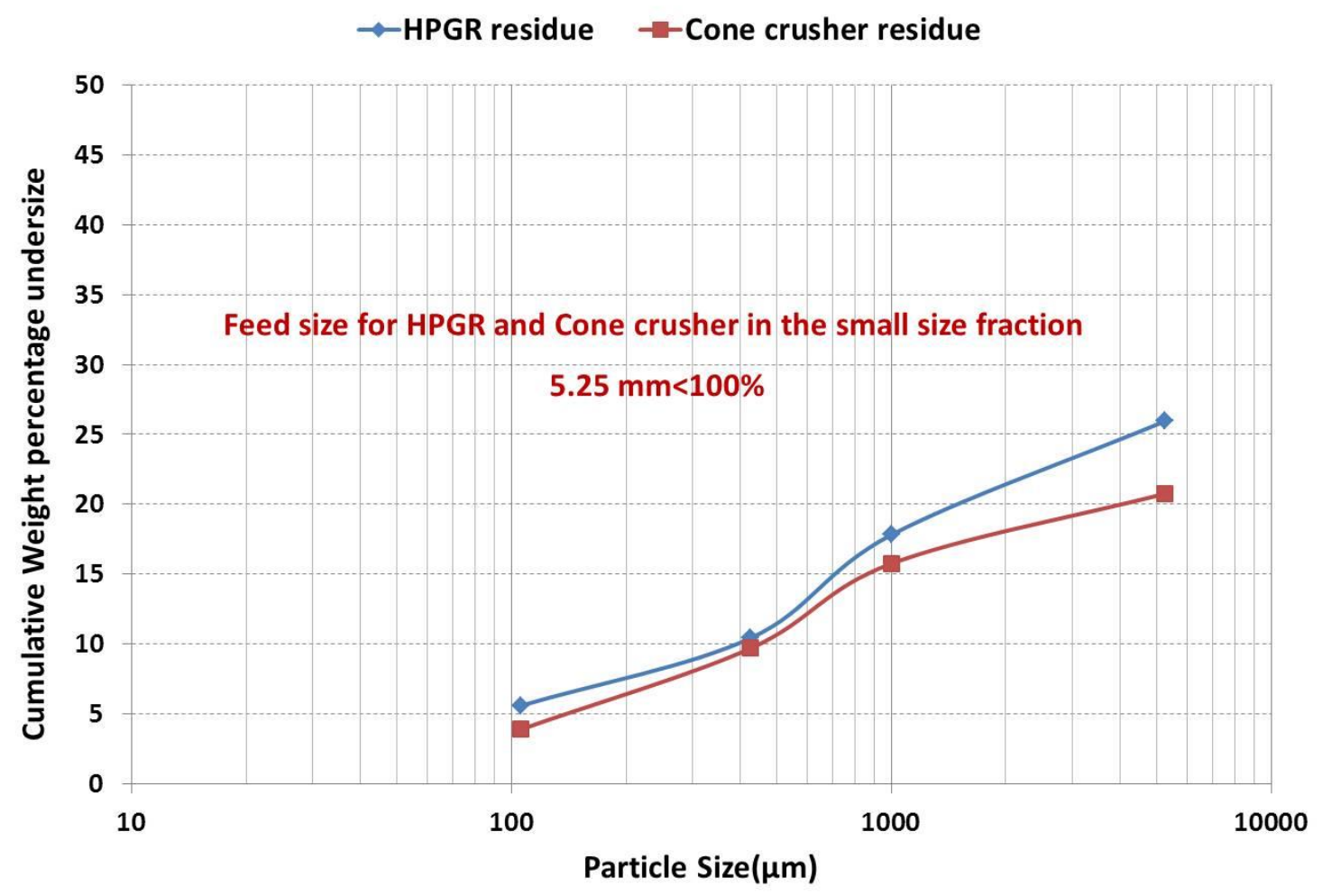

Figure 11: Changes in the PSDs of the HPGR and cone crusher products after 11 months leaching process in of the small size fraction.

Although the reactors were fed with specific size fractions, the residue had a size distribution containing even some fines. Results presented in the Figures 9-11 show that the residues from the reactors leaching the material prepared using the HPGR product contained more fine particles than the reactors, which were fed by cone crusher product. Table 5 shows that these differences were in order of $10.3 \%$ in large size fraction, $1.7 \%$ in the medium size fraction and $5.2 \%$ in the small size fraction. High fine particle fraction in the residue of the leach reactors related to the particles comminuted by HPGR could be due to the active crack network growth observed during the leaching. Since the surface of ore particles and their inner micro pores or cracks are damaged after reacting with sulfuric acid, some fine particles would be produced. The initial crack network in the particles comminuted by HPGR increases during the leaching process, which splits each single particles to two or more new ore particles and produces a particles size distribution different to the initial reactor feed. 
Table 5: Changes in the PSDs after 11 months leaching process in all three size fractions.

\begin{tabular}{|c|c|c|c|}
\hline \multirow{2}{*}{ Size fraction } & Before treatment & \multicolumn{2}{|c|}{ Residue of reactors } \\
\hline & cone crusher & HPGR & cone crusher \\
\hline Large & $0 \%<23 \mathrm{~mm}$ & $27.0 \%<23 \mathrm{~mm}$ & $16.7 \%<23 \mathrm{~mm}$ \\
\hline Medium & $0 \%<14 \mathrm{~mm}$ & $16.6 \%<14 \mathrm{~mm}$ & $14.9 \%<14 \mathrm{~mm}$ \\
\hline Small & $0 \%<5.25 \mathrm{~mm}$ & $26.0 \%<5.25 \mathrm{~mm}$ & $20.8 \%<5.25 \mathrm{~mm}$ \\
\hline
\end{tabular}

However, after leaching, under the coupled action of multiple factors, such as hydraulic power, gravity and chemical reactions, new partial fine particles flow downwards through the pore space among coarse particles and deposited at local areas and an extremely small amount of fine particles are transported out of the reactor by the solution (Kodali et al., 2011, Yang et al., 2008). Since in this study the solution reagent was introduced to the leach reactors from the bottom and there were basket frames at different level inside the leach reactors (Ghorbani et al., 2011d), there was no fine particles transportation out of the reactor. Thus, the ore particles size would have been redistributed in different levels of leach reactors.

The most fundamentally important aspect of heap leaching is permeability of the leach and even percolation of the lixivant solution throughout all the ore. Excessive amounts of the fines generated during the leaching process mostly with the product of HPGR, and their mobilization would result in reduced permeability as the leaching process progresses, which could have a negative effect on percolation especially over long periods of heap leaching operation. It would also prevent a uniform flow of the solution through the heaps.

\section{CONCLUSION}

In this study, X-ray CT has been used for investigation of the particles with high crack density produced by HPGR and the results were compared with those particles prepared using cone crusher.

The particle size distribution (PSD) of HPGR products from the three pressure settings were finer than the cone crusher product. It was observed that the specific grinding force was measured from 1.42 to 3.79 
$(\mathrm{N} / \mathrm{mm} 2)$, Although a finer product size distribution is expected as the pressure increases, the finest product in this work was obtained when HPGR was operated at the pressure setting of 95 bars which corresponded to the specific grinding force of $3.00(\mathrm{~N} / \mathrm{mm} 2)$.

The crack network in the particles comminuted by the HPGR appeared to increase during the leaching process. This accelerates reagent diffusion into the particles resulting in more metal extraction. However, no significant change was observed in the crack network for the particles comminuted using the cone crusher.

The micro-fracturing observed in the feed prepared using the HPGR could be the major reason for the differences in the zinc extraction in each of the size fractions evaluated. The results obtained in this work showed that 10 to $15 \%$ additional zinc leach extraction is possible.

Metal extraction for particles prepared using the HPGR operated at the pressure setting of 95 bars was higher than those comminuted with the HPGR at the pressure of 45 bars and 120 bars. This is an indication that there is an optimum operating pressure for the HPGR where the metal extraction rates are higher.

Evaluation of the leach reactors residue indicated significant changes in the PSD compared to the feed. The residues from the reactors leaching the material prepared using the HPGR product contained more fine particles than the reactors, which were fed by cone crusher product. These differences were in the order of $10.3 \%$ in large size fraction, $1.7 \%$ in the medium size fraction and $5.2 \%$ in the small size fraction. If excessive amounts of fines are generated during the leaching process, permeability is reduced as the leaching process progresses, which could have a negative effect on percolation especially over long periods of heap leaching operation. It would also prevent a uniform flow of the solution through the heaps.

\section{ACKNOWLEDGEMENTS}

The authors are grateful to Centre for Bioprocess Engineering Research (CeBER) and Centre for Minerals Research (CMR) (Department of Chemical Engineering, UCT), Bruce van der Nest (Anglo base metals) for organizing the ore sample, Paul Keanly (X-Sight X-ray Services), and Mintek (Minerals Processing Division) for their advice and support. Financial support from the South Africa Research Chair Initiative (SARChI) in Mineral Beneficiation, and a Research Niche Area (RNA) grant from the National Research Foundation (NRF) of South Africa are also acknowledged. 


\section{REFERENCES}

Acevedo, F., 2002, Present and future of bioleaching in developing countries. Electronic Journal of Biotechnology, 52-56.

Africa C J, Harrison S T L, Becker M and van Hille R. P., 2010, In situ investigation and visualisation of microbial attachment and colonisation in a heap bioleach environment: the novel biofilm reactor, Minerals Engineering, 23, 486-491.

Apling, A. and Bwalya, M. 1997, Evaluating high pressure milling for liberation enhancement and energy saving, Minerals Engineering, 10(9), 1013-1022.

Aydoğan, N. A., Ergün, L. and Benzer, H., 2006, High pressure grinding rolls (HPGR) applications in the cement industry. Minerals Engineering, 19(2), 130-142.

Barstlett, R. W., Simulation of ore heap leaching using deterministic models. Hydrometallurgy, 1992, 29 (13), 231-243.

Daniel, M. J., 2007, Energy efficient mineral liberation using HPGR technology, PhD thesis, University of Queensland.

Ghorbani, Y., Becker,M., Mainza,M., Franzidis,J-P., Petersen, J., 2011a, Large particle effects in chemical/biochemical heap leach processes - A review, Minerals Engineering, 24, 1172-1184.

Ghorbani, Y., Mainza, A.N., Petersen, J., Kalala, J.T., Becker, M., Franzidis, J-P., 2011b, Use of X-ray computed tomography to quantify the differences in cracks and pores in sphalerite ore particles when comminuted using an HPGR and cone crusher for heap leach feed preparation, Fifth international conference on: Autogenous and semiautogenous grinding technology, September 25-29, Vancouver, B.C., Canada.

Ghorbani, Y., Becker, M., Petersen, J., Mora, S. H., Mainza, A., Franzidis, J-P., 2011c, Use of X-ray computed tomography to investigate crack distribution and mineral dissemination in sphalerite ore particles, Minerals Engineering, 24, 1249-1257.

Ghorbani, Y., Petersen, Tupikina, O.V., Harrison, S.T.L., Becker, M., Mainza, A.N., Franzidis, J-P., 2011d, Investigation of the bioleaching of coarse sphalerite ore particles by a mixed culture of mesophilic chemolithotrophs in saturated leach reactors, the 19th International Biohydrometallurgy Symposium (IBS2011)., September 18-22, Changsha -China, Volume I, 249- 257. 
Hsih, C. S., Wen, S. B. and Kuan, C. C., 1995, An exposure model for valuable components in comminuted particles, International Journal of Mineral Processing, 43(3-4), 145-153.

Klymowsky, R., Patzelt, N., Knecht, J. and Burchardt, E., 2002, Selection and sizing of high pressure grinding rolls, Mular, A.L., Halbe, D., and Barsratt, D.J. (Eds.), Mineral Processing Plant Design, Practice, and Control, Society for mining, metallurgy, and exploration, Inc. (SEM), Littleton. Colorado, USA, 636-668.

Kodali, P., Depci, T., Nikhil Dhaw ,N., Wang,X., Lin, C.L., Miller, J. D., 2011, Evaluation of stucco binder for agglomeration in the heap leaching of copper ore, Minerals Engineering, 24, 886-893.

Liddell, K. C., 2005, Shrinking core models in hydrometallurgy: What students are not being told about the pseudo-steady approximation, Hydrometallurgy, 79 (1-2), 62-72.

Padilla, G. A., Cisternas, L. A. and Cueto, J. Y., 2008, On the optimization of heap leaching. Minerals Engineering, 21 (9), 673-683.

Petersen, J. and Dixon, D.G., 2007, Modelling and optimization of heap bioleach processes in Biomining, Rawlings, D.E. and Johnson D.B. (Eds.), Springer, Berlin, 153-175.

Pradhan, K.C., Nathsarma, K., Srinivasa, R., Sukla, L.B. and Mishra, B.K., 2008, Heap bioleaching of chalcopyrite: A review. Minerals Engineering, 21 (5), 355-362.

Rodríguez,Y., Ballester,A., Luisa, B., M., González, ., Angel, M. J., 2003, Study of Bacterial Attachment During the Bioleaching of Pyrite, Chalcopyrite, and Sphalerite, Geomicrobiology Journal, 20,131-141.

Schneider, L. C., Alves, K. V., Austin, G. L. 2009, Modelling the contribution of specific grinding pressure for the calculation of HPGR product size distribution, Minerals Engineering, 22,642-649.

Schönert, K., 1988A First Survey of Grinding with High-compression Roller Mills. International Journal of Mineral Processing, 22, 401-412.

Tromans, D. and Meech, J. A., 2002, Enhanced dissolution of minerals: Conjoint effects of particle size and microtopography. Minerals Engineering, 15 (4), 263-277.

Ubaldini, S., Veglió, F., Toro, L. and Abbruzzese, C., 1997, Biooxidation of arsenopyrite to improve gold cyanidation: study of some parameters and comparison with grinding. International Journal of Mineral Processing, 52 (1), 65-71.

Unlanda, G. and Szczelina, P., 2004, Coarse crushing of brittle rocks by compression. International Journal of Mineral Processing, 74, 209-223. 
Vegliò, F., Trifoni, M., Pagnanelli, F. and Toro, L., 2001, Shrinking core model with variable activation energy: a kinetic model of manganiferous ore leaching with sulphuric acid and lactose. Hydrometallurgy, 60 (2), 167-179.

Velardo, A., Giona, M., Adrover, A., Pagnanelli, F. and Toro, L., 2002, Two-layer shrinking-core model: parameter estimation for the reaction order in leaching processes. Chemical Engineering Journal, 90 (3), 231-240.

Watling, H.R., 2006, The bioleaching of sulphide minerals with emphasis on copper sulphides - A review. Hydrometallurgy, 84 (1-2), 81-102.

Yang, B.H., Wu, A.-X., Jiang, H.C. and Chen, X.S., 2008, Evolvement of permeability of ore granular media during heap leaching based on image analysis. Transactions of Nonferrous Metals Society of China, 18 (2), 426-433. 